\title{
Does Serum Vitamin D Level During Pregnancy Influence the Risk of Multiple Sclerosis?
}

\author{
Annenin Gebelikteki D Vitamini Düzeyi Çocuğunun Multipl Skleroz Geliştirme
} Riskini Artırır m1?

The increased risk of multiple sclerosis (MS) in adults with low vitamin D levels has been demonstrated previously in a large number of studies. However, a relatively lower number of studies have found an increased risk of MS with exposure to low vitamin D levels in utero, and some studies reported no effect (1).

A recent study by Munger et al. (1) used all serum samples taken from all pregnant women for routine tests and preserved since 1983 (Finnish Maternity Cohort). MS was diagnosed in 193 patients who were born between 1983-1991, serum 25(OH)D levels of their mothers were assessed using "chemiluminescence microparticle immunoassays", and results were compared with 326 mothers who had normal babies and were matched with the study group according to age and demographic features.

Analysis of the data revealed that $70 \%$ of the samples were taken before the $12^{\text {th }}$ week of pregnancy and $99 \%$ were taken before the $28^{\text {th }}$ week of pregnancy. Strikingly, children of mothers who were detected to have low vitamin D level $(<12.02 \mathrm{ng} / \mathrm{mL})$ at early periods of pregnancy had $90 \%$ higher risk of developing MS.
The strengths of this study include its population-based nature, which minimized its selection bias. However, these results do not give an idea about later months of pregnancy because the samples were mostly taken during the first trimester. Also, lower vitamin $\mathrm{D}$ levels in maternal blood sample do not always mean lower fetal vitamin D level. In addition, low vitamin D levels after birth in children who developed MS might have been responsible for the increased risk of MS.

In conclusion, despite all these uncertainties, the authors suggested that vitamin $\mathrm{D}$ replacement during pregnancy may decrease the risk of MS in offspring (1).

\section{Reference}

1. Munger KL, Åivo J, Hongell K, Soilu-Hänninen M, Surcel HM, Ascherio A. Vitamin D Status During Pregnancy and Risk of Multiple Sclerosis in Offspring of Women in the Finnish Maternity Cohort. JAMA Neurol 20161;73:515-519. 